\title{
A política externa da Rússia diante da crise na Síria
}

Diego Pautasso

Gabriel Adam

BRUNo Rocha Lima

Resumo: A diplomacia russa defende a preservação do governo sírio de Assad, entendendo que os "rebeldes" patrocinados pelos EUA e seus aliados levariam à desestabilização e ao avanço do fundamentalismo islâmico sunita na região. Enquanto a Rússia defende o combate ao jihadismo mediante alianças entre Síria, Irã e demais potências, os Estados Unidos e seus aliados preferem bombardeá-los.

Palavras-Chave: Rússia; Síria; Estado Islâmico.

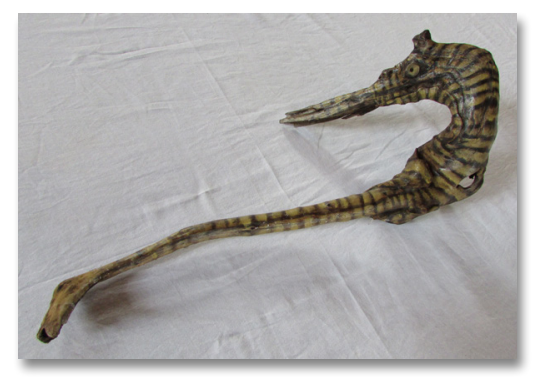

\section{Russia's foreign policy in face of the Syrian crisis}

\section{Diego Pautasso}

Doutor em Ciência Política pela UFRGS e professor de Relações Internacionais da UNISINOS.

dgpautasso@gmail.com

\section{Gabriel Adam}

Doutor em Ciência Política pela UFRGS e professor de Relações Internacionais da ESPM Sul e da UNISINOS. gabriel.pessin@gmail. com

\section{Bruno Rocha Lima}

Doutor em Ciência Política pela UFRGS e professor de Relações Internacionais da UNISINOS. blimarocha@gmail.com

\begin{abstract}
Russian diplomacy advocates for the preservation of the Syrian government of Assad, understanding that the "rebels" sponsored by the US and its allies would cause destabilization and the advancement of Sunni Islamic fundamentalism in the region. While Russia supports the fight against jihadism through alliances between Syria, Iran and other powers, the US and its allies prefer to bomb both of them.
\end{abstract}

Keywords: Russia; Syria; Islamic State.

RECEBIDO EM: $10 / 02 / 2016$

AProvaDo EM: 29/06/2016 


\section{INTRODUÇÃO}

O presente artigo aborda a política externa da Rússia voltada aos eventos relacionados à crise síria desencadeada a partir de 2011, no contexto da chamada Primavera Árabe. O entendimento é que muito mais do que um conflito interno ou uma guerra civil, a crise síria é impactada pela dinâmica regional, pela projeção de potências mundiais e regionais e pela atuação das organizações internacionais. Nesse sentido, propõe-se como argumento central do presente artigo que a Rússia atuou para preservar a estabilidade síria não apenas por seus interesses pragmáticos, ainda que eles naturalmente estivessem presentes nas ações de Moscou. Contudo, para além deles, a Rússia defendeu que a queda de Bashar Hafez al-Assad desestabilizaria não só o país, mas a região como um todo, postura diferente da adotada pelos Estados Unidos e seus aliados, os quais lideravam o apoio à insurgência civil, a partir de operações subterrâneas. Ademais, influi na posição russa o relacionamento mantido com Damasco por décadas.

A fim de embasar os argumentos sustentados no presente artigo, esse estará dividido da seguinte forma: primeiramente, sob a ótica do conceito de regime change, serão brevemente retomados os eventos que envolvem os países do Oriente Médio, desde o final de 2010, com destaque para o caso sírio. Em seguida, será analisada a política externa russa voltada à crise síria. Em um terceiro momento, serão abordados os desdobramentos para a região (inclusive, para a Europa) da adoção ou não das escolhas de Moscou, diante da crise na Síria.

\section{2 “PRIMAVERA ÁRABE” OU REGIME CHANGE?}

A crise síria foi considerada como parte da Primavera Árabe, iniciada na Tunísia em dezembro de 2010, tendo se espalhado para o mundo árabe, a partir do ano seguinte, em especial, mas não unicamente, para o Egito, a Líbia e a Síria. Enquanto na Tunísia e no Egito a onda de protestos e manifestações por mudanças políticas, sociais e econômicas teve origem quase que exclusivamente no ambiente doméstico, na Síria e na Líbia, os fatores internos se conjugaram com pressões externas de modo bastante evidente. 
No caso líbio, as ações da OTAN, a partir da aprovação da Resolução 1.358 do Conselho de Segurança da ONU, foram essenciais para a derrocada do regime de Muammar Kaddafi - posteriormente assassinado de forma bárbara. O fundamento da intervenção externa foi a Responsabilidade de Proteger (R2P), instituto formalmente lícito que prevê a possibilidade de violação de soberania de um Estado por decisão da ONU, em casos de ameaça à população local ou à segurança coletiva. Em função do uso alargado e politicamente interessado, o R2P, muitas vezes, perde legitimidade, pois acaba servindo tão-somente para conceder um verniz de legalidade à imposição da força por parte das grandes potências. No caso líbio, ficou evidente que a sua utilização tratou-se apenas de um recurso diplomático-jurídico, voltado a sustentar interesses intervencionistas que redundaram em desestabilização política, fragmentação da unidade territorial e destruição da economia do país africano (PAUTASSO; AZEREDO, 2011).

Os protestos na Síria tiveram início em 2011, após a queda de Ben Ali, na Tunísia, e de Hosni Mubarak, no Egito. Desde então, as mesmas forças envolvidas na intervenção ocorrida na Líbia, lideradas pelos Estados Unidos, procuram derrubar o Presidente Assad. Diferentemente da Líbia, cuja unidade estava assentada na liderança de Kaddafi sobre um conjunto de tribos, a liderança síria de Assad (que sucedeu seu pai Hafez, agindo como líderes seculares) assentou-se numa estrutura estatal mais organizada, erigida a partir de um pacto entre a alta oficialidade de carreira vinculada ao Baath (Partido Nacional Árabe) e a liderança não menos importante dos alauítas, um ramo do islamismo de origem xiita radicado na região em associação a outras minorias religiosas e grupos sociais com religiosidade menos ortodoxa (mesmo quando sunita). Vale lembrar que a alta oficialidade vinculada ao Baath é uma herança não programática dos tempos do pan-arabismo, sob inspiração nasserista, ainda que mais ideologizada na sua origem.

O aparelho estatal e o sistema político sírios, apesar da centralização de poder, eram muito mais modernos e laicos que os demais da região, permitindo que os diversos grupos étnicos e credos religiosos convivessem com razoável padrão de civilidade. Com efeito, é inegável que, apesar das insatisfações intrínsecas 
ao jogo político, as manifestações foram, num primeiro momento, insufladas pelo contexto da Primavera Árabe e, depois, claramente patrocinadas por forças externas, cujo objetivo sempre foi a deposição de Bashar Al-Assad. Não é difícil constatar tais intenções a partir do conjunto de manchetes, boletins e reportagens veiculadas no Ocidente, nas quais o presidente sírio é constantemente demonizado ${ }^{1}$ - em oposição evidente ao silêncio diante das mais retrógradas petroditaduras árabes do Golfo Pérsico, cujo maior exemplo é justamente a Arábia Saudita, leal aliada de Washington, desde sua fundação, em 1932, e que, em janeiro de 2016, executou 47 por decapitação.

Assim, as manifestações rapidamente evoluíram para uma escalada de violência, com a presença cada vez maior de combatentes jihadistas não-sírios com recursos, armamentos e equipamentos claramente enviados do exterior. A radicalização criou cisões que, associadas aos discursos e ações voltadas a depor Assad, organizadas de dentro e de fora da Síria, tornaram qualquer espécie de arranjo entre governo e oposição muito difícil de ser obtido.

1 A leitura das reportagens publicadas ainda em 2011 demonstra bem o imaginário que se pretendia construir acerca dos distúrbios na Síria. Entre os títulos de alguns textos tem-se: "Syria's Government Kills 2,000 during Protests, Says Clinton" (The Guardian, 05 de agosto de 2011, link: http://www.guardian. co.uk/world/2011/aug/05/syrian-government-killed-protests-clinton); "Syria Sends In Tanks to Storm Center of Rebellious City" (New York Times, 04 de agosto de 2011, disponível em: http://www.nytimes.com/2011/08/04/ world/middleeast/04syria.html?_r=1\&ref=world); "Obama to toughen stance on Syria with call for Assad's departure" (The Guardian, 10 de Agosto de 2011, disponível em: http://www.guardian.co.uk/world/2011/aug/10/obama-syriaassad-departure); "Syrian forces kill nine after peace plan agreed" (Independent, 04 de novembro de 2011, disponível em: http://www.independent.co.uk/news/ world/middle-east/syrian-forces-kill-nine-after-peace-plan-agreed-6256916. html); "Syria nuclear weapons site revealed by UN investigators" (The Guardian, 01 de novembro de 2011, disponível em: http://www.guardian.co.uk/ world/2011/nov/01/syria-nuclear-arms-site-revealed). O contraponto a tal visão do conflito era fornecido em fontes de mídia de menor alcance. Neste sentido, Pierre Piccinin publicou artigo intitulado Lies and Media Manipulation Regarding Protests Movement in Syria, no qual, a partir de uma investigação in loco na Síria, constatou que havia protestos em partes do país, mas, na época, a vida cotidiana permanecia relativamente inalterada e nada do caos alardeado nos grandes veículos internacionais era visto nas ruas do país (disponível em: http://globalresearch.ca/index.php?context=va\&aid=25865). 
A desejada queda de Bashar Al-Assad e a colocação de um novo mandatário mais afeito aos interesses dos Estados Unidos e de países europeus, como França e Inglaterra, seguia o roteiro do que ocorrera no Iraque em 2003, ou seja, uma ação de regime change. Essa estratégia é utilizada frequentemente por parte dos Estados Unidos, há mais de um século, pelo menos desde a derrubada da monarquia havaiana em 18932. Segundo Kinzer (2007), a intervenção em países mais fracos com o intuito de modificar seus governos é realizada pelos Estados Unidos para atingir os seguintes objetivos (que naturalmente podem estar conjugados ou se mesclarem): impor sua ideologia, aumentar seu poder (o que pode envolver determinantes geopolíticas) ou obter controle sobre recursos naturais valiosos (KINZER, 2007, p. 1). Além dos casos em que os Estados Unidos dão início a arranjos e manobras cuja meta é depor líderes estrangeiros, o autor cita os seguintes métodos de regime change adotados.

Os Estados Unidos usam uma variedade de meios para persuadir outros países a fazerem o que demandam. Em vários casos, a persuasão reside em táticas de diplomacia premiadas pelo tempo, como oferecer prêmios aos governos que apoiam os interesses americanos ou ameaçar de retaliação aqueles que se opõem. Algumas vezes, eles defendem regimes amigos contra ódios e revoltas populares. Em mais de poucos lugares, eles têm secretamente apoiado golpes ou revoluções organizados por outros. Duas vezes, nos contextos das guerras mundiais, eles ajudaram a varrer velhas ordens mundiais e impor novas (KINZER, 2007, p. 01).

No tocante ao regime de Bashar Al-Assad, as ações dos Estados Unidos e seus aliados europeus assumiram várias formas. Primeiro, deve-se destacar que os governos norte-americanos sempre tiveram uma relação de desconfiança diante do governo

2 Curiosamente, a primeira tentativa estadunidense de intervenção na política de outro país com o objetivo de trocar um governo hostil ocorreu em Trípoli, hoje capital da Líbia. Insatisfeito com as cobranças por proteção aos navios estadunidenses no Mediterrâneo, realizadas pelo pasha de Trípoli, o Presidente Thomas Jefferson iniciou um conflito que durou entre 1801 e 1805 . Pouco antes do final da guerra, o cônsul estadunidense na Tunísia, William Eaton, tramou um golpe que colocaria o irmão exilado do paxá de Trípoli no poder. Antes que tal movimiento fosse realizado, Washington e Trípoli chegaram a um acordo e deram fim ao conflito (HERRING, 2008). 
sírio, em função de sua postura autonomista e de seus alinhamentos com o Irã e o grupo Hezbollah. Pode-se citar como exemplo um telegrama de 27 de fevereiro de 2006, vazado pelo site Wikileaks ${ }^{3}$ em 30 de agosto de 2011, em que o diplomata da embaixada norte-americana em Damasco, Stephen Seche, relata os efeitos da operação "Anunciando a Democracia", conduzida pelos Estados Unidos para depor Assad.

Segundo, com o espiral de violência na Síria, ficou mais evidente a tentativa norte-americana de depor o governo Assad. Desde o início, o governo russo, através de seu chanceler Sergei Lavrov, alertou que o problema de fundo se referia ao desrespeito do direito internacional, decorrente das inadmissíveis ações do Ocidente voltadas a "mudar regimes". Lavrov também questionou a razão da ofensiva contra o regime sírio, uma vez que a situação no Iêmen era até mais delicada ${ }^{4}$. Enquanto isso, a secretária de Estado dos Estados Unidos, Hillary Clinton, reafirmava a necessidade de fomentar a oposição "rebelde" a Assad, justamente com apoio de Arábia Saudita, Catar e Turquia ${ }^{5}$ - os dois primeiros, históricos apoiadores do jihadismo sunita. Nitidamente, como diz Anderson (2015, p. 125), a opção de Washington foi apostar numa guerra por procuração para evitar o desgaste e os custos provocados pela intervenção no Iraque.

Foram inúmeras as tentativas de aprovação de intervenção externa via Conselho de Segurança. Contudo, elas foram seguidamente rechaçadas por Rússia e China, ao contrário do caso líbio, quando Moscou e Pequim se abstiveram na votação da Resolução 1.358. Em paralelo, Washington procurou apoiar e insuflar a oposição síria, basicamente constituída por sunitas jihadistas, milicianos de matriz wahabbita (a mesma da Arábia Saudita) e integristas

3 Ver íntegra do telegrama disponível em: https://wikileaks.org/ cable/2006/02/06DAMASCUS760.html\#. Acesso em 12/09/2015.

4 Ver informações no site da agência Russia Today, disponível em: http:// actualidad.rt.com/actualidad/view/29218-Mosc\%C3\%BA-critica-intentosoccidentales-de-cambiar-reg\%C3\%ADmenes-indeseables-del-mundo-arabe. Acesso em 06/11/2014.

5 Ver detalhes no site da revista Carta Capital, disponível em: http://www. cartacapital.com.br/internacional/eua-confirmam-ajuda-a-rebeldes-na-siria. Acesso em 16/09/2015. 
salafistas. Mais do que dissidentes das forças armadas, intitulados líderes do Exército Livre da Síria, tratava-se de uma força irregular insurrecional estreitamente ligada à Al Qaeda. Aos jihadistas do leste sírio, somaram-se aqueles sunitas alijados do poder, após o colapso do regime baathista de Saddam Hussein, por meio da intervenção de $2003^{6}$. Portanto, no caso sírio, as atitudes norte-americanas ficariam no meio termo entre apoiar golpes organizados por outros e protagonizar a retirada de um governo inimigo, posto que, se é verdade que havia uma oposição local ao governo Bashar Al-Assad, a sua conformação mais heterogênea e virulenta não teria se organizado sem a ajuda de Washington.

As disputas geopolíticas em torno do desenrolar da situação síria possuem raízes profundas e arraigados interesses internacionais. Após a Segunda Guerra Mundial, já alçados à condição de líderes do campo capitalista/ocidental da Guerra Fria, os Estados Unidos procuraram se inserir com força no Oriente Médio. O objetivo imediato, em meados do século XX, era garantir o fluxo de petróleo para si e para seus aliados. Deve-se ressaltar que, mesmo historicamente pouco dependente do petróleo do Oriente Médio, os Estados Unidos entenderam que sua segurança energética, no longo prazo, e os destinos do sistema internacional seriam fortemente condicionados pelos recursos energéticos fósseis. Aqui cabe lembrar que regiões importantes do mundo com economias fortes e consolidadas, como a Europa Ocidental, ou em crescente expansão econômica, como o Leste Asiático, dependem grandemente do petróleo oriundo do mundo árabe/persa. Logo, a influência sobre a produção de hidrocarbonetos do Magred e do

6 O país mantido coeso sob a liderança de Saddam não poderia ter outro destino senão a tendência à fragmentação territorial e à desestabilização política. Primeiro, a parte xiita passou governar formalmente o Iraque com a gestão do primeiro-ministro Nouri Al-Maliki, a partir de 2006, após o término do governo de transição gerido pela ocupação estrangeira, liderada pelos EUA desde 2003. Em agosto de 2014, Maliki foi substituído por outro xiita, o primeiroministro Haider al Abadi, cujo objetivo é forjar um governo de unidade nacional. Contudo, a parte sunita do país caiu sob o controle de jihadistas comandada pelo sheik Abu Bakr al-Baghdadi na região fronteiriça, com a Jordânia e a Síria. E a outra porção do território tem se organizado como proto-Estado, sob o controle do Governo Regional Curdo (KRG), de forma independente, desde a intervenção norte-americana. 
Machrek e suas rotas de escoamento é de extrema importância para os Estados Unidos, pois podem induzir eventuais rivais à escassez estrutural de energia (AMINEH; HOUWELLING, 2005, p. 80). Um adicional não desprezível às considerações geopolíticas envolvendo o petróleo é a garantia de lucros que a comercialização de um recurso tão precioso gera para as empresas estadunidenses de energia, cuja influência sobre a Casa Branca aumenta consideravelmente, desde as crises de energia dos anos 1970.

No período da Guerra Fria, havia a preocupação norte-americana com o surgimento de regimes que se tornariam próximos de Moscou, ao menos durante certos períodos (Egito, Argélia, Iêmen do Sul, Líbia e a própria Síria), o que trouxe para a Península Arábica e o Norte da África a dinâmica de disputas por alianças e influência nos respectivos contextos. Também há de se destacar a proteção de Israel por parte dos Estados Unidos, iniciada pelo reconhecimento do novo Estado, em 1948, e acentuada sobremaneira a partir da década de 1960. A referida preocupação estadunidense, portanto, gerou uma das alianças mais duradouras entre uma potência ocidental e um país localizado na Península Arábica, a qual somente não é mais antiga do que a selada entre Washington e Riad.

O enfraquecimento da URSS nos anos 1980 e o final da Guerra Fria permitiram aos Estados Unidos ampliarem consideravelmente sua presença no Oriente Médio. Nessa direção, a Guerra Iraque-Kuwait de 1991 abriu espaço para uma escala intervencionista intermitente e os atentados de 11/09 de 2001 forneceram o argumento para o Governo George W. Bush aprofundar o intervencionismo sob a égide da denominada Guerra Global ao Terror. Contudo, mesmo sem entrar em minúcias, é possível perceber a ambiguidade da postura estadunidense na sua Guerra ao Terror, uma vez que alguns grupos jihadistas e claramente fundamentalistas são apoiados por Washington em determinados momentos, enquanto outros, laicos e/ou que ascendem pela via eleitoral, são hostilizados. O contexto da guerra do Iraque de 2003, da intervenção na Líbia e da guerra civil na Síria exemplificam essa contradição: nos dois primeiros casos, governos laicos foram substituídos por outros de matiz religiosa bem mais acentuada, enquanto, na 
Síria, os grupos apoiados por Washington são reconhecidamente jihadistas fundamentalistas.

Tal pragmatismo tem sido central à política externa estadunidense, em especial no Oriente Médio, região que pela sua instabilidade e importância foi considerada pelo consultor do Partido Democrata, Zbgniew Brzezinski, como o ponto central do Arco das Crises (BRZEZINSKI, 1997, p. 53). Nota-se que essas crises fazem parte da estratégia de ação de Washington para manter seu domínio e legitimar suas bases militares e suas intervenções no Oriente Médio. Em outras palavras, é preciso ressaltar que há um critério de seleção nos atos de Washington: os alvos de suas ações não são as petromonarquias conservadoras, mas sim os governos modernizantes que almejam autonomia em relação ao Ocidente. Como destaca Losurdo (2006), a retórica do liberalismo tem servido historicamente para legitimar intervenções sob a alegação da defesa da democracia, dos direitos humanos e das liberdades civis, como atestam novamente os casos de Iraque, Líbia e Síria. Para tanto, isto inclui, frequentemente, a capacidade de construir inimigos e vilanizar atores sob os mais diversos conceitos, como, por exemplo, terrorismo e fundamentalismo (LOSURDO, 2010).

Neste contexto, a guerra civil síria ingressa no radar dos Estados Unidos, que adotam um pragmatismo similar ao visualizado na Guerra Fria, quando a CIA havia apoiado o talibã para se opor ao regime filo-socialista afegão, embasado pelos soviéticos. Como chama atenção Bandeira (2013, p. 386), dessa vez, Estados Unidos, França, Grã-Bretanha e aliados do Oriente Médio, sobretudo a Turquia e as autocracias de estilo medieval Salafi-Wahabi de Qatar e Arábia Saudita, financiavam mercenários para derrubar o governo sírio, enquanto a mídia ocidental construía a imagem de um conflito civil decorrente do choque entre rebeldes democratas contra uma ditadura impiedosa. A massiva campanha midiática visava a legitimar uma intervenção da OTAN, tal como ocorrido na Líbia.

Ademais, segundo Bandeira (2013, p. 373), a queda de Assad permitiria: suprimir a presença da Rússia, através de suas bases navais na Síria de Latakia e Tartus (esta operada desde 1971); desarticular o eixo de resistência conformado por Irã-Síria-Hezbollah; 
interromper o fluxo de armas para este último, núcleo da resistência xiita contra Israel no Líbano; isolar completamente o Irã, após as intervenções no Afeganistão, Iraque e Síria; e conter a presença de China e Rússia na região. O chanceler sírio Walid al Muallen vai mais longe ao acusar a ingerência estrangeira e regional de fortalecer o terrorismo, ao impedir a resolução do problema. O ministro ainda colocou em dúvida as intenções dos Estados Unidos em destruir o Estado Islâmico, pois jamais chamou o Conselho de Segurança da ONU ou os países-chave da região (Síria, Irã e Rússia), para a construção de uma solução eficaz ${ }^{7}$.

\section{A REAFIRMAÇÃO DA RÚSSIA NO ENTORNO REGIONAL}

Os Estados Unidos ampliaram sua presença no Oriente Médio no Pós-Guerra Fria, em alguma medida pela falta de um contendor de peso com influência na região, como o exercido pela URSS, entre os anos 1950 e 1980. O conflito na Síria - assim como as discussões acerca do programa nuclear iraniano - marcam, contudo, um retorno progressivo da Rússia para o tabuleiro do Oriente Médio. Há, pois, diversos fatores que dão substância à crescente assertividade da Rússia na cena internacional e, nesse caso, no conflito sírio, em diversas oportunidades, mostrando capacidade de confrontar a linha de atuação norte-americana.

O primeiro ponto a destacar é que a ascensão de Putin tem impulsionado uma reafirmação internacional da Rússia. Para tanto, o governo russo tem reorganizado setores chaves da economia, como o de hidrocarbonetos e o bélico. Em paralelo à reconstrução econômica, depois dos trágicos resultados do período Yeltsin, o governo russo tem buscado assumir maiores responsabilidades no plano internacional, como atestam diversos discursos e documentos. No documento "Conceito da Política Externa da Federação Russa"8, de fevereiro de 2013, está clara a defesa

7 Ver notícia no site Russia Today, disponível em: http://actualidad.rt.com/ actualidad/view/148894-canciller-siria-terrorismo-coalicion-internacional. Acesso em 06/12/2014.

8 Ver íntegra do documento em: http://www.mid.ru/bdomp/ns-osndoc.nsf/1 e5fOde28fe77fdcc32575d900298676/869c9d2b87ad8014c32575d9002b1c38!Op enDocument. Acesso em 06/12/2014. 
da Rússia como um dos polos de um novo mundo que assume formas cada vez mais policêntricas. Já no discurso de Putin na sessão do Clube Valdai - cujo sugestivo título era Ordem Mundial: Ou novas regras ou vale-tudo ${ }^{9}$ - é possível observar a diferenciação da posição russo em relação à atuação dos Estados Unidos. Putin disse que os vencedores da Guerra Fria negligenciaram qualquer concertação para estabelecer um novo equilíbrio do poder, preocupados com suas próprias necessidades e interesses. O efeito tem sido a subversão do direito internacional, através de interpretações arbitrárias e enviesadas das normas legais, fomentando conflitos através do apoio a grupos declarados neofascistas (Ucrânia) e a islamistas radicais - como os grupos armados (mercenários) patrocinados pelo governo dos Estados Unidos para depor Assad. Disse ainda que a tentativa excepcionalista dos Estados Unidos de exercer a condição unipolar torna-se cada vez mais distanciada e divorciada da realidade e em contradição com a diversidade do mundo (PUTIN, 2014).

O segundo ponto é diretamente relacionado com o Oriente Médio, no qual a antiguidade da presença russa é notória. Já no século XVIII, o império Russo travava conflitos com o Império Otomano pelo controle da região que hoje forma a Ásia Central. No século seguinte, na esteira da decadência dos otomanos, russos e britânicos enfrentaram-se na disputa conhecida como O Grande Jogo, cujo prêmio era justamente a porção nordeste do Império Otomano, além de disputarem zonas de influência na Pérsia, ainda que esta não tenha sido colonizada por nenhuma das duas potências europeias (MANSFIELD, 2013, p. 158) ${ }^{10}$. Durante a Guerra Fria, a fronteira sudoeste soviética era dividida com Turquia e Irã, dois países que passaram boa parte daquele período aliados aos Estados Unidos. Ainda que hoje a ligação fronteiriça da Rússia com

9 Ver detalhes da declaração disponível em: http://www.tlaxcala-int.org/ article.asp?reference $=13867$. Acesso em 06/12/2014.

10 No ano de 1813, Pérsia e Império Russo assinaram o Tratado e Golestan, pelo qual aquela cedeu a este os territórios de Baku (hoje Azerbaijão) e da Geórgia. Junto com a Armênia (na época pertencente ao Império Otomano), Azerbaijão e Geórgia formam o Cáucaso do Sul, região que pertenceu à URSS e hoje é considerada pela Rússia como pertencente a seu entorno estratégico. 
o Oriente Médio se dê apenas com o Irã, e via Mar Cáspio, é inegável que a região lhe é muito próxima. Ademais, a atual presença massiva dos Estados Unidos no Machrek e no Magreb é percebida por Moscou como uma tentativa de Washington de cercar e constranger a atuação da Rússia no sistema internacional.

O terceiro ponto possui contornos civilizacionais e de política doméstica. As vitórias diante do Império Otomano geraram ao Império Russo o controle sobre o Cáucaso (Norte e Sul) e a Ásia Central, regiões que pertenceram à União Soviética (URSS). Hoje, os povos do Cáucaso Norte permanecem na Federação Russa, enquanto os países do sul-caucasiano (Geórgia, Azerbaijão e Armênia) e do centro-asiático (Cazaquistão, Quirguistão, Tadjiquistão, Turcomenistão e Uzbequistão) pertencem ao que Moscou considera sua zona de influência. Com a exceção da Geórgia e da Armênia, todos os demais países mencionados possuem maioria populacional muçulmana e alguns deles detêm grupos armados com estreita relação a congêneres, localizados no Oriente Médio. Na própria Federação Russa, o contingente de muçulmanos atingia 10\% da população em 2010, e, tendencialmente, deve crescer para 11,4\% em 202011. Portanto, o potencial de efeitos para a Rússia dos desdobramentos do mundo muçulmano e, em especial, do Oriente Médio é significativo, podendo, inclusive, impactar em sua estabilidade interna.

O quarto ponto refere-se às disputas pelas reservas de petróleo e gás natural da região. A Federação Russa é exportadora de hidrocarbonetos e tem interesses objetivos no preço, nos mercados consumidores e nas rotas de recursos energéticos fósseis. Assim como a guerra na Ucrânia pode afetar o suprimento da Europa, a instabilidade no Oriente Médio afeta a construção das rotas petrolíferas do Cáspio e centro da Ásia. Ressalte-se que a Rússia tem buscado cada vez mais os mercados do Leste da Ásia para diversificar seus mercados.

11 Fonte: Pew Research Centrer. Endereço eletrônico: http://www.pewforum. org/2015/04/02/religious-projection-table/2010/percent/all/. Último acesso em 09 de abril de 2015. 
O quinto ponto refere-se diretamente às políticas russas diante do conflito sírio. Primeiro, cabe destacar que a ligação próxima entre Moscou e Damasco remonta ao período da Guerra Fria, mais especificamente após os anos 1970, quando Hafez Al-Assad tomou o poder na Síria e buscou uma aproximação com o governo soviético, no contexto da Guerra Fria (PRIMAKOV, 2009). Com efeito, as relações entre Rússia e Síria preservaram-se após a desintegração da URSS, de modo que a marinha russa continuou a operar no porto sírio de Tartus, cujo início das operações remonta a 1971. Ademais, a Rússia continua a ser um dos principais fornecedores de material bélico para a Síria ${ }^{12}$. Dessa forma, a acusação do governo dos Estados Unidos de que a Rússia possui presença militar na Síria causa espécie, dado que o relacionamento russo-sírio é histórico e que não é exclusividade russa fornecer equipamentos bélicos para países da região. Como afirmou Lavrov, Moscou fornece armas de fogo, lançadores de granadas e veículos blindados às forças do governo sírio de modo a "prevenir, na Síria, o roteiro líbio e outros acontecimentos dolorosos que tiveram lugar na região por causa da obsessão dos nossos parceiros ocidentais com as ideias de alterar os regimes indesejáveis"13.

\section{A POSIÇÃO RUSSA E OS EFEITOS DO CONFLITO SÍRIO}

Em função de todos os fatores suscitados que demonstram as razões do interesse russo no Oriente Médio e na Síria, em especial, a Rússia voltou a ter uma atuação importante no Oriente Médio tanto no conflito sírio quanto nas negociações relativas ao acordo nuclear com o Irã. Embora o Ocidente tenha optado por demonizar Putin, como reconheceu Kissinger (2014), e atribuir à Rússia

\footnotetext{
12 Segundo dados do SIPRI, a Síria é a $12^{\circ}$ maior compradora de armamentos russos, no período de 1991 a 2014, totalizando US\$ 1,517 milhões. Em compensação, a Rússia é a maior fornecedora de armas para a Síria no período, pois, de todo os armamentos importados pelo Goiverno Bashar Al Assad, 46,9\% são provenientes de empresas rusas. Cf. informações disponíveis em: http://armstrade.sipri.org/armstrade/html/export_values.php. Acesso em $13 / 04 / 2014$.

13 Ver reportagem do Sputnik Brasil, disponível em: http://br.sputniknews. com/mundo/20150910/2086961.html. Acesso em 16/09/2015.
} 
o perfil de país belicista e expansionista, avesso à governança global, o caso do conflito sírio é elucidativo da diferença de postura em comparação com os Estados Unidos e seus aliados.

Por um lado, a posição russa conseguiu evitar uma intervenção por meio do Conselho de Segurança da ONU, buscando soluções negociadas para o conflito sírio. Em junho de 2011, o chanceler russo Sergei Lavrov já expressava sua contrariedade a qualquer autorização do Conselho de Segurança da ONU ao emprego de forças estrangeiras na Síria, destacando o potencial desestabilizador desse ato para a região ${ }^{14}$. Em razão disso, a Rússia, em mais de uma oportunidade, vetou as resoluções do Conselho de Segurança da ONU que abriam espaço para a intervenção na Síria. A visão dos Estados Unidos restringia-se a considerar o veto russo (e chinês) um vergonhoso ato de proteção do tirano Assad, como expressou a embaixadora dos Estados Unidos na ONU, Susan Rice ${ }^{15}$. Aliás, a posição do brasileiro Paulo Sérgio Pinheiro, presidente da Comissão de Inquérito da ONU que investiga crimes de direitos humanos na Síria, sempre foi contra uma intervenção estrangeira, entendendo que não há solução militar e, nesse caso, suas consequências seriam catastróficas. Ainda segundo ele, apesar do regime autoritário, a sociedade síria era relativamente aberta e funcionava, sem fundamentalismos e com respeito às minorias religiosas ${ }^{16}$.

Por outro, os Estados Unidos e seus aliados forneceram armas, recursos e treinamento aos rebeldes sírios e aprofundaram a guerra civil e a divisão do país. Não é a primeira vez que os Estados Unidos se utilizam de grupos islamitas para levar adiante seus interesses geopolíticos. As relações são mais sinuosas, como destacou Michel Chossudovsky, pois os Estados Unidos e seus aliados

14 Ver detalhes no site da agência Russia Today disponível em: http:// actualidad.rt.com/actualidad/view/27975-Lavrov-Rusia-vetara-cualquierresoluci\%C3\%B3n-que-autorice-uso-indiscriminado-de-fuerza. Acesso em 06/11/2014.

15 Ver detalhes no site da BBC disponível em: http://www.bbc.co.uk/ portuguese/noticias/2012/02/120204_siria_onu_fn.shtml. Acesso em 06/11/2014.

16 Entrevista concedida ao jornal Folha de S. Paulo, disponível em: http:// www 1.folha.uol.com.br/mundo/2013/09/1342442-horror-na-siria-vai-muitoalem-das-armas-quimicas-diz-presidente-de-comissao-da-onu.shtml. Acesso em 06/11/2014. 
apoiam e combatem o islamismo radical conforme o contexto. Antes, dera o apoio à Al Qaeda, durante a guerra afegano-soviética (1979-89), atualmente, o Estado Islâmico e Al Nusra são fruto do financiamento ocidental, através da CIA estadunidense, do MI6 britânico, do Mossad israelense e dos serviços de inteligência do Paquistão e Arábia Saudita, para derrubar o governo Assad ${ }^{17}$.

A diferença de postura entre as duas potências ficou bastante visível no final do ano de 2013. Sob a alegação de que o governo de Assad havia utilizado armas químicas contra sua população, Barack Obama discursou, afirmando que era seu desejo realizar intervenção militar na Síria, ainda que isto não envolvesse desembarque de tropas naquele país. Explicitamente, Obama declarou que estava confiante em agir sem esperar os inspetores da ONU (que investigariam a culpa pelos ataques) e que estava confortável em seguir seu plano sem a aprovação do Conselho de Segurança, que, até então, estava completamente paralisado e sem vontade de fazer Assad responder por seus atos (OBAMA, 2013). De imediato, a Rússia se opôs à manobra estadunidense, mediante declarações feitas na reunião do G20 ocorrida em 04 de setembro daquele ano. Oito dias depois, Putin escreveu artigo no New York Times alegando que, caso o plano de Obama fosse levada adiante, a ONU estaria desprestigiada e prestes a seguir o mesmo destino da Liga das Nações. Também sustentou que o potencial ataque dos Estados Unidos, ao qual se opunham diversos países e líderes religiosos, como o Papa, resultaria na morte de mais vítimas inocentes e no crescimento da violência, que se espalharia para além das fronteiras sírias e causaria uma nova onda de terrorismo. Igualmente, lembrou que o Governo Assad estava disposto a colocar seu arsenal químico sob o controle internacional para posterior destruição. Por fim, clamou para que Moscou e Washington trabalhassem juntos para que tal objetivo fosse alcançado (PUTIN, 2013). A postura assertiva russa deteve um ataque militar direto dos Estados Unidos no território sírio.

17 Ver notícia no site Russia Today, disponível em: http://actualidad.rt.com/ actualidad/view/148894-canciller-siria-terrorhttp://actualidad.rt.com/ actualidad/view/147616-aspectos-estado-islamico-eeuu-mentiras. Acesso em $06 / 12 / 2014$. 
Quanto às armas químicas do governo sírio, Rússia e Estados Unidos elaboraram junto à ONU um plano para sua entrega e destruição, o qual foi concluído ainda em 2014 - evitando a precipitação da intervenção estrangeira.

Contudo, a guerra civil não findou. Pelo contrário, ela se agravou devido, sobretudo, à opção ocidental de demover o governo Assad, através de operações subterrâneas voltadas a insuflar a oposição. O primeiro dos desdobramentos de tal postura que merece destaque é a criação do Estado Islâmico, sob liderança do ex-professor universitário Abu Bakr al-Baghdadi. Sua origem reside na destruição do Iraque desde 2003 - do consequente descontentamento dos sunitas alijados do poder - e na revolta dos sunitas jihadistas na Síria a partir de 2011, após a captura das cidades iraquianas de Fallujah, Tikrit e Mossul - desta última tomada, em junho de 2014, pilharam mais de 425 milhões de dólares (COCKBURN, 2015). Com efeito, a rede wahabita aliada ao Estado Islâmico, composta por mercenários de todos os quadrantes, se fortalece atuando na Líbia, Egito e Iêmen, com anuência e colaboração dos aliados ocidentais (Turquia, Arábia Saudita, Monarquias do Golfo e Paquistão). Não causa surpresa que David Petraeus, o influente ex-chefe da CIA e ex-comandante das forças americanas no Iraque e Afeganistão, tenha proposto cooperar com os jihadistas da Frente al-Nusra, filial da al-Qaeda na Síria, para derrubar os jihadistas do Estado Islâmico ${ }^{18}$.

O próprio combate ao Estado Islâmico igualmente demonstra a diferença de atitude entre Moscou e Washington. A ambivalência estadunidense de patrocinar grupos e países que fomentam o terrorismo não se vislumbra nas ações russas. Durante meses, a Rússia procurou apoiar o governo Assad contra o Estado Islâmico apenas com o fornecimento de armas, enquanto procurava apoio diplomático. Conforme destacado por Casula (2015), Moscou organizou três rodadas de negociação com as partes do conflito sírio no ano de 2015 (em janeiro, abril e agosto) ${ }^{19}$. Ainda no

18 Ver notícia no site The Daily Beast, disponível em: http://www.thedailybeast. com/articles/2015/08/31/petraeus-use-al-qaeda-fighters-to-beat-isis.html. Acesso em 16/09/2015.

19 Casula destaca que tais rodadas eram criticadas por alguns grupos sírios, por englobarem apenas os oposicionistas aceitos, pelo governo (Casula, 2015). 
campo diplomático, Putin discutiu sobre o conflito com líderes de países como Egito, Jordânia, Arábia Saudita, Turquia, Israel e Emirados Árabes, entre agosto e outubro do mesmo ano. Além disto, a Rússia foi uma das líderes das rodadas de negociação de Viena, as quais reúnem 17 países para debater a guerra civil síria e o problema do Estado Islâmico.

Todavia, na medida em que os avanços diplomáticos para resolver a crise síria eram morosos ou quase inexistentes e que a coalizão ocidental formada e liderada pelos Estados Unidos, em setembro de 2014, para debelar o Estado Islâmico, não obtinha avanços significativos na Síria, Moscou optou por ingressar diretamente no conflito da Síria contra o grupo jihadista, alegadamente após receber pedido formal de auxílio do governo de Assad ${ }^{20}$. A participação militar russa iniciou com consentimento do governo sírio a partir de ataques aéreos a posições do Estado Islâmico, em 30 de setembro de 2015. Desde então, a Força Aérea Russa tem alternado entre ataques contra os oponentes e entrega de ajuda humanitária às localidades sírias cercadas pelo inimigo. Segundo um comunicado do governo russo de 15 de janeiro de 2016, desde o início da operação, foram socorridos 217 povoados, equivalentes a mais de mil quilômetros quadrados, sendo que, apenas nos primeiros onze dias deste ano, a aviação russa fizera 311 voos de combate e bombardeara 1.097 instalações de terroristas na Síria ${ }^{21}$. Em outro comunicado, o representante oficial do Ministério da Defesa da Rússia, major-general Igor Konashenkov, fez questão de diferenciar os ataques aéreos russos dos estadunidenses. Segundo sua visão, os ataques da Força Aérea Russa na Síria são aplicados contra posições terroristas, apenas quando confirmadas as informações, através de vários canais, não sendo realizados caso haja risco à vida de civis pacíficos. Ao citar a correspondente da CNN no Pentágono, Konashenkov, afirmou que o comando americano

20 O governo sírio alega que as investidas da coalizão liderada por Washington frequentemente são dirigidas contra as forças governamentais sírias. Ademais, cabe destacar que tal coalizão não recebeu autorização nem da ONU nem de Damasco, para bombardear territorio sírio.

21 Ver notícia em http://br.sputniknews.com/mundo/201601 15/3306201/Daeshperde-controle-sobre-217-povoacoes.html\#ixzz3xiNhb35V. Acesso em 15/01/16. 
decide sobre a aplicação dos ataques aéreos sob a condição de que o número de civis mortos não seja superior a 50 pessoas ${ }^{22}$. Mesmo que seja necessário relativizar a posição do major-general russo, as recorrentes perdas de vidas por danos colaterais nas guerras e intervenções estadunidenses, ao longo dos anos, confirmam o pouco caso de Washington com a vida dos povos que supostamente almeja proteger.

A investida militar russa tem tido desdobramentos importantes, para além do campo militar. No dia 31 de outubro de 2015, um avião civil russo caiu no Egito, o que resultou na morte de 224 pessoas. O Serviço Secreto Russo considerou a queda fruto de um ataque terrorista, o qual foi reivindicado pelo Estado Islâmico ${ }^{23}$. Quase um mês depois, em 24 de novembro de 2015, um avião russo tripulado por dois homens foi abatido pela Turquia, sob a alegação de que violara o espaço aéreo turco, o que foi negado pelo Kremlin. A clara provocação de um país membro da OTAN e o silêncio de todos seus membros evidenciam a intencionalidade; mas, mesmo assim, Moscou optou por retaliar a Turquia no campo econômico. No campo político-diplomático, a Rússia tem experimentado avanços. Uma parceria entre Putin e o Rei Abdullah II, da Jordânia, foi celebrada a fim de selar a cooperação dos dois países na luta contra o Estado Islâmico. No mesmo sentido, foi realizado acordo entre Moscou e Paris, após a capital francesa ser alvo de atentados terroristas em 13 e 14 de novembro de 2015 (KORZUN, 2016). As conquistas militares e diplomáticas russas não passaram despercebidas por Washington. Segundo David Ignatius, articulista do Washington Post, a Rússia emerge como uma parceira diplomática e militar essencial para os Estados Unidos na Síria, o que já teria rendido canais de colaboração e acordos de atuação no país árabe (IGNATIUS, 2016).

Outro desdobramento importante da guerra civil síria é a onda de refugiados e deslocados. Segundo dados da ONU de outubro de 2015, são mais de 4,1 milhões de refugiados sírios, sendo

22 Ver notícia em http://br.sputniknews.com/mundo/20160115/3307609/ diferenca-operacoes-russia-eua-na-siria.html\#ixzz3xiLy6SFo. Acesso em 19/01/16.

23 Ver notícia em http://sputniknews.com/russia/20151117/1030241199/ a321-crash-explosive-explodes.html\#ixzz3xnBeTfow. Acesso em 17/11/15. 
2,1 milhões no Egito, Iraque, Jordânia e Líbano e 1,9 milhões na Turquia - fora os 7,5 milhões de deslocados no interior do país ${ }^{24}$. Em função da força dos meios de comunicação ocidental, a crise somente se tornou grave quando quase um milhão de refugiados adentraram a Europa em 2015, sendo que cerca de 500 mil sírios, 200 mil afegãos e 70 mil iraquianos, conforme a ACNUR ${ }^{25}$. Ironicamente, quase $80 \%$ desses refugiados são de países que sofreram intervenções dos países ocidentais. E, nesse sentido, destacou Assad, o Ocidente é contraditório ao lamentar pelos refugiados e, ao mesmo tempo, dar suporte aos terroristas desde o início da crise. Destacou, ainda, o Presidente Sírio que é necessário eliminar as causas primeiras desse problema, ou seja, o terrorismo islâmico e a destruição da infraestrutura decorrente da guerra civil ${ }^{26}$. Ao invés disso, o Ocidente continua a trabalhar para derrubar Assad, enquanto bombardeou a região em agosto de 2014, como fazem os Estados Unidos, sob alegação de defesa humanitária de assírios, yazidis e demais minorias na antiga Mesopotâmia. Obviamente os atentados terroristas na Europa alimentam a islamofobia, que, por sua vez, fortalece os grupos de extrema direita, em uma espiral de irracionalidade crucial para ocultar suas origens imperialistas.

A terceira consequência é o remodelamento das fronteiras do Grande Oriente Médio. A desintegração da Síria e do Iraque pode representar o redesenho do Acordo Sykes-Picot, estabelecido entre França e Grã-Bretanha, para dividir e retalhar os espólios de dominação do Império Otomano, derrotado na Primeira Guerra Mundial. As redefinições das fronteiras pós-coloniais têm se dado com o apoio ocidental às elites mais conservadoras, como os beduínos transformados em monarcas e financiadores do jihadismo sunita, em detrimento das elites modernizadoras, tais como os nasseristas, baahtistas, entre outros. Pode-se dizer, na linha de Kissinger (2015, p. 117), que se aprofunda uma contradição

24 Mais informações disponíveis no site da ACNUR: http://www.acnur.org/ t3/que-hace/respuesta-a-emergencias/emergencia-en-siria/. Acesso em: 03/07/2016.

25 Ver dados da agencia da ONU: http://www.acnur.org/t3/portugues/ noticias/noticia/um-milhao-de-refugiados-e-migrantes-fugiram-para-aeuropa-em-2015/

26 Ver notícia no site Sputnik Brasil disponível em: http://br.sputniknews. com/opiniao/20150916/2136196.html. Acesso em 16/09/2015. 
da região, qual seja, a de fortalecer o islamismo militante como mecanismo de organização política, em oposição às formas estatais laicas e pan-arabistas de viés vestfaliano.

Em suma, o desenrolar dos acontecimentos tem revelado não só que a Rússia está a preservar o direito internacional, a soberania e a via político-diplomática para resolver o conflito sírio, diferentemente dos Estados Unidos e seus aliados, como acerta ao apontar o poder desestabilizador que as ações estadunidenses têm para a região. Apesar do apoio da Rússia na sustentação da aliança baathista-alauíta-xiiita e do governo iraniano, a fragilização do governo sírio tem contribuído para a formação e expansão do domínio político e territorial do Estado Islâmico, bem como para a onda de refugiados na região e na Europa. Essa posição da Rússia converge com o documento "Conceito da Política Externa da Federação Russa"27, que expressava a preocupação em relação à violação dos princípios fundamentais do direito internacional, seja pelas sanções unilaterais e outras medidas coercitivas, incluindo agressão armada, fora do âmbito do Conselho de Segurança da ONU, seja pela interpretação arbitrária das resoluções, visando a derrubar autoridades legítimas em Estados soberanos, sob o pretexto de proteger a população civil. Enfatizava também que tal prática não tem sido capaz de eliminar profundos antagonismos socioeconômicos, étnicos e outros que causam conflitos, além de agravar controvérsias interestatais e fragilizar as organizações internacionais.

\section{CONSIDERAÇÕES FINAIS}

Apesar da vilanização da Rússia, o tempo tem demonstrado que o país eurasiático tinha a política mais consequente para lidar com a crise síria. A Rússia buscou sempre uma solução política entre governo e oposição, a resolução da questão das armas químicas pela via diplomática e a defesa da prerrogativa das organizações internacionais (e os principais atores regionais como Síria e Irã), para lidar com o Estado Islâmico. Os Estados Unidos

27 Ver íntegra do documento em: http://www.mid.ru/bdomp/ns-osndoc.nsf/ 1e5f0de28fe77fdcc32575d900298676/869c9d2b87ad8014c32575d9002b1c38!O penDocument. Acesso em 06/12/2014. 
e seus aliados, por sua vez, têm apresentado uma política errática para a região, cujos resultados estão se avolumando na forma da proliferação do fundamentalismo sunita, da desorganização econômico-política de diversos países (Síria, Iraque, Líbia) e da onda de deslocados e refugiados.

O dilema posto é que os Estados Unidos não podem lidar com a crise e o fundamentalismo na região sem o apoio da Síria, Irã e Rússia e, simultaneamente, sem impor limites aos financiadores do jihadismo - Arábia Saudita, Qatar e Turquia. Ademais, o bombardeio aleatório da região, como realizado e proposto por lideranças ocidentais, além de gerar mais ressentimentos, reações e refugiados, enfraquece soluções políticas construídas coletivamente por meio da ONU. Fica a dúvida se o fundamentalismo islâmico é um problema para os Estados Unidos ou se é parte da estratégia de manutenção da hegemonia, a partir duma necessária recriação da Guerra Global ao Terror que preenche a lacuna deixada pelo inimigo vermelho dos tempos da Guerra Fria.

\section{REFERÊNCIAS}

AMINEH, M. P. and HOUWELLING, H. Caspian Energy: Oil and Gas Resources in the Global Market. In AMINEH, M. P. and HOUWELling, H. Central Eurasia in Global Politics: Conflict, Security and Development. Leiden: Brill: 2005.

ANDERSON, Perry. A política externa norte-americana e seus teóricos. São Paulo: Boitempo, 2015.

BANDEIRA, Luiz. A Segunda Guerra Fria. Rio de Janeiro: Civilização Brasileira, 2013.

CASULA, Phillip. Russia Beetween Diplomacy and Military Intervention: The Syrian Conflict through Russian Eyes Revisited. Zurich: Russian Analytical Digest n 175, p. 6-10, 16 November 2015.

COCKBURN, Patrick. A origem do Estado Islâmico. São Paulo: Autonomia Literária, 2015.

HERRING, George C. From Colony to Superpower: U.S. Foreign Relations Since 1776. New York: Oxford University Press, 2008.

IGNATIUS, David. America May be Doomed to Cooperate with Putin. Washington Post. Washington, 2016. Disponível em https:// 
www.washingtonpost.com/opinions/america-may-be-doomedto-cooperate-with-putin/2016/01/12/799774ce-b97e-11e5-99f3184bc379b12d_story.html. Acesso em: 03 jul. 2016.

KINZER, Stephen. Overthrow: America's Century of Regime Change From Hawaii to Iraq. New York: Times Books, 2007.

KISSINGER, Henry. To settle the Ukraine crisis, start at the end. Washington Post, 05 de março de 2014.

KORSUN, Peter. Moscow's Growing Influence in Middle East: Jordan Set up War Room with Russia. Moscow, 2016. Disponível em: $\quad$ http://www.strategic-culture.org/news/2016/01/19/ moscow-growing-influence-middle-east-jordan-set-up-warroom-with-russia.html. Acesso em 19 jan. 2016.

LOSURDO, Domenico. A linguagem do Império. São Paulo: Boitempo, 2010.

\& Letras, 2006.

Contra-história do Liberalismo. Aparecida: Ideias MANSFIELD, Peter. A History of Middle East. New York: Penguin Books, 2013.

OBAMA, Barack. Statement by the President on Syria (Transcript). Washington, 2013. Disponível em https://www. whitehouse.gov/the-press-office/2013/08/31/statementpresident-syria. Acesso em: 03 jul. 2016.

Ordem mundial. Rio de Janeiro: Objetiva, 2015.

PAUTASSO, D.; AZEREDO, R. Expansão do poder dos Estados Unidos: o caso da Líbia. Tensões Mundiais. v. 7. n. 13. Fortaleza: EdUECE/ Banco do Nordeste, 2011. p. 169-192.

PRIMAKOV, Yevgeni. Russia and the Arabs. New York: Basic Books, 2009.

PUTIN, Vladimir. A Plea for Caution from Russia. New York Times. New York, 2013. Disponível em: http://www.nytimes. com/2013/09/12/opinion/putin-plea-for-caution-from-russiaon-syria.html?pagewanted=all\&_r=0. Acesso em: 03 jul. 2016.

Intervenção na sessão do Clube Valdai sobre Ordem

Mundial: Ou novas regras ou vale-tudo. Sochi: 2014. Disponível em: http://www.tlaxcala-int.org/article.asp?reference=13867. Acesso em: 03 jul. 2016. 